\title{
Bite force in vertebrates: opportunities and caveats for use of a nonpareil whole-animal performance measure
}

\author{
ROGER A. ANDERSON ${ }^{1 *}$, LANCE D. MCBRAYER ${ }^{2}$ and ANTHONY HERREL ${ }^{3}$ \\ ${ }^{1}$ Biology Department, Western Washington University, Bellingham, WA 98229-9160, USA \\ ${ }^{2}$ Department of Biology, Georgia Southern University, Box 8042, Statesboro, GA 30460, USA \\ ${ }^{3}$ Department of Biology, University of Antwerp, Universiteitsplein 1, B-2610 Antwerpen, Belgium
}

Received 12 September 2006; accepted for publication 6 June 2007

\begin{abstract}
Measurements of whole-organism performance traits have been useful in studies of adaptation and phenotypeenvironment correlations. Bite force capacities may be tightly linked to both the type and magnitude of the ecological challenges of food acquisition, mate acquisition, and antipredation in vertebrates. In the present study, we present technical details on bite meters and on measuring bite forces. The ability to take reliable measurements depends on specific features of the measuring device and on where in the mouth the bite is applied. Using both previously available and original data, we demonstrate several ecologically and evolutionarily relevant features of bite force measurements. First, maximal bite forces are repeatable among individuals across all vertebrates studied to date. Second, in ectotherms such as lizards, maximal bite forces are affected by body temperature and motivational states. Third, bite forces are strongly correlated with head size and shape. Fourth, bite forces correlate with features of prey of vertebrates. Finally, bite forces are linked to male dominance and correlated with social-display structures. Thus, bite force performance measures can be used as 'traits', and thus be used in integrative studies at multiple levels of organismal biology. Accordingly, bite force data will help our understanding of the functions, capacities, and evolution of jaw-cranial musculoskeletal systems. Moreover, a plethora of opportunities exist for the use of bite force measurements, and if methods are carefully applied, several levels of organismal and ecological organization can be integrated to aid our understanding of the ecology and evolution of vertebrate taxa. (C) 2008 The Linnean Society of London, Biological Journal of the Linnean Society, 2008, 93, $709-720$.
\end{abstract}

ADDITIONAL KEYWORDS: diet - male-male combat - sexual dimorphism.

\section{INTRODUCTION}

Multicellular organisms are the sum of integrated form-function complexes (Bock \& von Wahlert, 1965). Comparisons among animals varying in formfunction complexes for their relative abilities to perform ecologically relevant tasks (e.g. evading predators and capturing prey, sensu Huey \& Stevenson, 1979) enhance our understanding of the evolution of the enormous morphological diversity of animals (Arnold, 1983; Wainwright, 1991). Locomotor performance traits, for example, have been useful tools for analysing the design, function, and evolution of locomotor systems in vertebrates (Irschick \& Garland, 2001). Furthermore, analyses of locomotor performance traits have provided insights into our

*Corresponding author. E-mail: roger.anderson@wwu.edu understanding of evolutionary and functional tradeoffs and their roles in the evolution of phenotypic variation (Vanhooydonck, Van Damme \& Aerts, 2001; Van Damme et al., 2002).

Similarly, performance measures associated with the vertebrate jaw system provide insights with respect to vertebrate ecology and evolution. The jawcranial musculoskeletal system is a hallmark formfunction complex of vertebrates, used to capture, subdue, and orally process prey, and to obtain mates (Motta \& Kotrschal, 1992; Korf \& Wainwright, 2004; Lappin \& Husak, 2005) and, presumably, to defend against predators. Bite forces explicitly can be assumed to be tightly linked to design features of the jaw-cranial system, and thus bite forces could be used as performance measures at the whole-animal level. If bite force is an ecologically relevant performance measure, then variation among taxa in bite 
forces should be linked to variation among taxa in the intensity of ecological challenges (e.g. prey, predator, or sexual competitor) that they encounter. For many species, maximal bite force may be an infrequently used, but exceedingly important factor in the outcome of agonistic and mating encounters (Schoener, 1966; Cooper \& Vitt, 1993; Lailvaux et al., 2004; Huyghe et al., 2005), resource use (Hernandez \& Motta, 1997; Herrel et al., 1999b; Herrel etal., 2001a, Herrel, De Grauw \& Lemos-Espinal, 2001b; Grubich, 2003), and breadth of the resource niche (Herrel, Van Damme \& DeVree, 1996; Herrel et al., 1999a).

Variation among individuals in bite performance may be linked to variation in fitness (Wainwright, 1991). If bite force is a reliable whole-animal performance trait within a population, however, several conditions must be met. First, maximal bite forces must be repeatable for individuals under similar conditions; significant changes in maximal bite force may relate to ontogenetic or seasonal changes in response to hormones (Herrel \& O'Reilly, 2006; Herrel et al., 2006; Irschick et al., 2006). Second, variation among individuals must correlate with measurable morphological features. Individuals with the largest heads will presumably possess larger adductor muscle masses (Herrel et al., 1996, 1999a; Herrel, McBrayer \& Larson, 2007); thus, these individuals should also be able to bite harder. Third, variation in bite force among individuals must correlate with a measure more directly related to fitness, such as the net rate of energy intake when foraging (Anderson \& Karasov, 1988), number and quality of mates acquired (Anderson \& Vitt, 1990; Lappin \& Husak, 2005), or success in antipredation (Marquez \& Cejudo, 2000).

The present study examines the collection, use, and efficacy of bite force as a whole-animal performance measure and reviews the relevant data collected previously. We describe two experimental procedures for measuring bite force in vivo. We present new data demonstrating how transducers can be tested for accuracy and precision. We then show how bite force data from a variety of vertebrates that face different sets of ecological challenges help to answer a variety of questions. The study foci are to present caveats in collecting and interpreting bite force data (e.g. motivation to bite) and to explore how bite force data could be used to test ecological and evolutionary hypotheses.

\section{MATERIAL AND METHODS}

\section{BITE FORCE METERS AND THEIR CALIBRATION}

One bite force meter (i.e. that of R. A. Anderson) was modelled after the detailed specifications of Sinclair (1983). The bite plates consist of two alloy steel plates (each $1.5 \mathrm{~mm}$ thick) clamped onto a solid metal block. Foil strain gauges are bonded to both the upper and lower plates. The gauges convert the amount of deformation (strain) of the plates to a change in resistance in a wheatstone bridge circuit. This change in resistance is calibrated to be directly proportional to the compressive force in Newtons (see below). The meter is equipped with an analogue output connection so that the data may be displayed, stored, and analysed directly on a computer. Depending on the size of the mouth of the study species, transducers of various dimensions (total length, width, or height), or adjustable transducers (see below) may be constructed. Similar transducers have been used to measure bite forces in mammals (Binder \& Van Valkenburgh, 2000; Thompson, Biknevicius \& German, 2003), lizards (McBrayer, 2002, 2004; McBrayer \& White, 2002), and small alligators (Erickson, Lappin \& Van Vliet, 2003).

This style of transducer must be calibrated prior to use. The linearity of the relationship between the output ( $\mathrm{mV}$ or $\mathrm{N}$ ) should be quantified for both a mass applied to the plates and the location of this force along the length of the plates. For novel data presented herein on the lizards Tupinambis teguixin and Gekko gecko, the meter was standardized at $9.8 \mathrm{~N} \mathrm{~kg}^{-1}$ force at $10 \mathrm{~mm}$ from the tip of the plates. The placement of these bites at this calibrated location was confirmed for each bite session, or that session was excluded. Eight different masses were applied at this location and the output was highly repeatable and linear $\left(R^{2}=0.99 ; y=0.0478 x+\right.$ $0.0075)$. The bite plates were also calibrated at each 2-mm increment along its full length. These results were also highly linear for each of four masses tested (0-26 mm, 14 locations; $P<0.001$ for each mass; $R^{2}=0.999$ for $0.494 \mathrm{~kg}$ and $1.994 \mathrm{~kg}, R^{2}=1.00$ for $0.994 \mathrm{~kg}$ and $4.049 \mathrm{~kg} ; y$ intercepts for increasing masses $=6.467,13.089,26.529,53.646 ;$ slopes for increasing masses $=-0.169,-0.330,-0.683,-1.333$ ) so, for any bite location, the transducer voltage (force) output was corrected for the leverage-dependent bite location. These calibration steps are essential to ensure that the force values reported are actual values and thus will be comparable among individuals and/or species. Biting on catheter-type pressure transducers or on two always-parallel plates would not require such careful calibration to compensate for bite location on the device (Huber \& Motta, 2004).

The second bite force meter (i.e. that of A. Herrel) is based on a piezo-electric force transducer [Kistler, types $9203( \pm 500 \mathrm{~N})$ and $9207( \pm 5000 \mathrm{~N})]$, mounted into a custom-built holder. Attached to the transducer is a screw that is connected to a top plate. The top plate pivots across a fulcrum (Mitutoyo 150-802 micrometer head) mounted onto the holder and 
adjustable in height. Bite plates of varying thickness and dimensions are mounted on the top plate and holder and provide a surface for the animal to bite on. The point of application of the bite forces on the plates is standardized by the length of the bite plates. Detailed descriptions and illustrations of the set-up are provide elsewhere (http://webhost.ua.ac.be/ funmorph/bite force transducers.html). The transducer is connected by means of a high impedance cable (Kistler type 1631C) to a 9-V battery operated, handheld charge amplifier (Kistler type 5995A) with hold function. This piezo-electric transducer is precalibrated and shows a linear response throughout its entire range. Thus, transducer output needs to be corrected for the lever system (fulcrum-to-bite distance) of the bite plates only. Transducers of this style have been used to measure bite forces in birds (Herrel et al., 2005a, b), sharks (Huber et al., 2005), caecilians (Measey \& Herrel, 2006), large alligators (Erickson et al., 2003), lizards (Herrel et al., 2001a; Lappin \& Husak, 2005), bats (Aguirre et al., 2002; Dumont \& Herrel, 2003), mice (Byron et al., 2004), and turtles (Herrel, O'Reilly \& Richmond, 2002; Herrel \& O’Reilly, 2006).

\section{THE BITE SESSIONS}

For the methods-testing data presented herein on lizards (T. teguixin and G. gecko), individuals were tested in five to ten bite force sessions, each session involving multiple bites and with typically at least $30 \mathrm{~min}$ of rest between sessions. Between sessions, lizards were maintained at their field active body temperatures, which are close to the optimal performance temperature for bite force (Bennett, 1985; A. Herrel, unpubl. data). These and most other vertebrates tested for bite force readily open their jaws in response to being hand-held, regardless of whether in recent (weeks for G. gecko) or long-term captivity (months for T. teguixin). Putatively vigorous bites also were reported for long-term captive mammals (Binder \& Van Valkenburgh, 2000; Thompson et al., 2003) and alligators (Erickson et al., 2003). Bite plates were positioned symmetrically under the upper tooth rows. The typical subject's response was to bite quickly and vigorously as soon as one of the bite plates touched a tooth row. More vigorous bites from individuals with anomalously weak bites were induced to bite harder when light taps were applied to the side of the jaws.

Bite plates were covered with a thin layer of material (chamois) to prevent tooth damage and slipping. Moreover, the bite location of the anterior teeth could be marked and checked to ensure that the teeth did not fully pierce the covering and encounter metal. The combination of a thin pliable covering, the gape distances required to bite, and the movement of the bite plates whereas biting mimics the texture, size, and resistance of a conspecific or animal prey item.

Given the biomechanics of the jaw lever system, forces measured closer to the angle of the jaw will be greater than those measured closer to the jaw tips. Thus, we explored the feasibility of measuring bite forces along (anteriorly posteriorly) the tooth row in some smaller lizards. Rubber-coated metal rods were glued transversely on the plates and the rods were placed precisely against the teeth at a given distance along the tooth row. These narrow rods could be placed at pre-calibrated locations along the bite plates so that maximal bite forces at varying positions along the jaw (front to back) could be obtained. Most bite force studies have measured force in the front of the jaws because it is relatively easy to get animals to bite at a standard location nearer the front (but see also Dumont \& Herrel, 2003), and it is more difficult to fit the bite bars between teeth in the rear of the mouth, particularly in fish (Grubich, 2005). Investigators must report where along the length of the jaw (e.g. distance anterior to the angle of the jaw) so that maximal bite force values can be compared among studies.

\section{RESULTS AND DISCUSSION}

\section{BITE POSITION AND GAPE ANGLE}

Effects of bite position are typically strong for the lizards we tested herein and in other vertebrates tested to date. In a moderate-sized lizard [adult G. gecko, $149 \pm 18 \mathrm{~mm}$ snout-vent length (SVL)], bite force near the tip, just posterior to the nostrils, averages $78.5+1.6 \%(N=7$, range $73-84 \%)$ of the bite force midway towards the joint. Likewise, in several species of bats, the bite force approximately doubles when moving from the anterior canine posteriorly to the molars (Dumont \& Herrel, 2003). Thus, the standardization of bite position, and the accurate recording and reporting of the point of application of bite force (e.g. by video; Erickson et al., 2003; Thompson et al., 2003; Lappin et al., 2006a) or tooth-mark locations (McBrayer \& White, 2002), are essential results to be included in analyses. Moreover, documenting bite positions will help focus research on where the forces are applied and the function of the bite. Indeed, the high bite force in the rear of the jaw may be an epiphenomenon for some vertebrates, whereas the rear bite forces may be the primary selected feature in others. The morphotype of the jaw-cranial complex and magnitude of bite force, for example, may vary with bite function, such as would be associated with killing or capture bites at the front of the mouth (e.g. the ambush and subduing of prey) or crushing bites near the back of the mouth (e.g. crushing the skull or 
exoskeleton of prey; McBrayer \& White, 2002; Korff \& Wainwright, 2004), or shearing bites from mid-mouth to the back (e.g. herbivores processing fruit or plant matter or breaking bones along the carnassials in mammals).

Another consideration is that the jaw-cranial complex may show unique adaptations to proficiently exert bite force along only one side of the jaw as might be needed in prehension of evasive prey or crushing or shearing small hard-bodied prey. For example, Summers (2000) showed that myliobatid stingray bite asynchronously, have a unique jaw muscle lever system, and rigid symphyses. Each of these modifications are presumed to permit the great bite forces needed for crushing hard prey (mollusks). For animals specialized for such tactics, the consequences for bite force capacity may differ from animals that typically bite bilaterally (i.e. equally across both rami of the jaw). The adaptive features of unilateral forceful biting may comprise more than just flexibility of the symphysis (Herrel, Aerts \& De Vree, 2000; Lieberman \& Crompton, 2000). Moreover, cranial kinesis, which is common birds and lizards (Frazetta, 1962; Bock, 1964; Arnold, 1998), may also influence bite force. Bite forces in taxa with cranial kinesis may vary differently with sustained bites, bite locations, or gape sizes, compared to bite forces in taxa without kinetic skulls (Herrel et al., 1999c, 2000).

If the influence of bite position, gape, body temperature (see below) and motivational state (see below) of study taxa are known, then portable force transducers are effective tools for measuring bite force in vertebrates. Their simple design delivers accurate and precise force values, as well as a rapid, real time responses to subtle changes in bite force (McBrayer \& White, 2002). These bite force meter designs have been successfully used to measure bite forces of species in most major vertebrate taxa (mammals: Binder \& Van Valkenburgh, 2000; Dumont \& Herrel, 2003; Thompson et al., 2003; squamates: Herrel et al., 1999a, b, 2001a, b, Herrel, Vanhooydonck \& Van Damme, 2004; McBrayer, 2002, 2004; birds: van der Meij \& Bout, 2004a; Herrel et al., 2005a, b; turtles: Herrel et al., 2002; crocodiles: Erickson et al., 2003; sharks: Huber \& Motta, 2004; Huber et al., 2005). The various transducer designs allow for flexibility; animals from the size of hatchling lizards $(0.3 \mathrm{~g})$ to adult hyena (Crocuta crocuta, Binder \& Van Valkenburgh, 2000) and adult American alligators (Alligator mississippiensis, Erickson et al., 2003) can be tested. Moreover, the same system can easily be used to measure grasping force of claws of crabs (Levinton \& Judge, 1993; Schenk \& Wainwright, 2001) and scorpions (A. Herrel \& A. P. Summers, unpubl. data).

Alternative, indirect methods have been used to predict and estimate maximal bite forces that con- scious, motivated animals would attain. Measuring muscle lever mechanics or the physiological cross section of a muscle or bone strain have been used as presumably reliable estimates of the maximal bite force (Herrel et al., 1996; Herrel, Aerts \& De Vree, 1998a, b; Herrel et al., 1999a, 2005c; Taylor, 2000, 2001; Ross et al., 2007). Another useful approach is to measure the force necessary to crush prey, and to compare that force with the force generated by muscle stimulation or EMG-based estimates of crushing forces (Wilga \& Motta, 2000; Huber \& Motta, 2004; Korff \& Wainwright, 2004; Huber et al., 2005). Stimulating muscles to tetany with a force transducer positioned along the tooth row is a viable approach to test taxa in which individuals are typically unwilling to bite a transducer. For example, Huber \& Motta (2004) directly tested four different morphological and physiological methods (none measured bite force of conscious individuals) and showed that the methods yielded statistically equivalent results. These authors, however, presented caveats for the use of each method. Given that the precision, accuracy, and repeatability of any method used for measuring bite force should be considered, the present study aims to demonstrate the utility, reliability, and caveats in measuring bite force of animals performing voluntary bites.

Bite velocity, in addition to bite force (strength), may be an important feature for prehension of prey. For simple lever systems with all other factors being equal, velocity and force represent biomechanical trade-offs (Levinton \& Allen, 2005): long jaws produce higher angular velocity, whereas shorter jaws produce higher force outputs. Alternatively, bite force could be an epiphenomenal result of high bite velocity. Thus, high-speed video would be useful for documenting the capture (prehension) phase of predator-and-prey interactions; the predator's bite velocities can be compared with similarly documented bite velocities and concurrent bite forces on the bite bars. In the context of vector mechanics analyses, however, the statics of bite force should be much easier to reliably measure than the dynamics of bite forces associated with rapidly moving jaws (Beer et al., 2006). Moreover, the dynamic process of biting to establish mouth contact with the prey and to begin the act of prey prehension may grade or switch into a more static (and typical) measure of maximal bite force when the mouth is closed and pressing on the prey in the completion of prehension and as prey are subdued.

Sustained bites may be necessary for holding struggling prey or mates. The variation among animals in force and duration of the holding bite could be compared with variation among individuals in maximal bite force. We examined holding forces during 1-min bite sessions of our largest seven tegu lizards (T. teguixin). Between the $6.4 \pm 0.5$ bites per minute, 
holding bites of $11.9 \pm 1.4 \mathrm{~N}$ (range 9-20, 263$313 \mathrm{~mm}$ SVL, three males, four females) occurred between the brief, strong bites (mean $\pm \mathrm{SE}$ maximal bites $=106 \pm 12 \mathrm{~N}$ ). Thus, conspecifics varying in size and maximal bite force had remarkably similar sustained bite forces. Sustained bites in some species may be performed with a relatively closed mouth, whereas, for other species, the gape size when biting may be considerable; hence, musculoskeletal design may differ for such species. Notably, variation in the relative abundance of muscle fibre types, as well as cross-sectional area of adductors, patterns of pennation, and origin-and-insertion, all may be features of fine tuning for sustained bites, and may represent trade-offs for bite force.

The maximum bite force also should be compared with the ability to maintain a sustained, full mouth grip, particularly if the gape angle is large. The full mouth grip is seen not only in prey capture, such as when the long-nosed leopard lizard, Gambelia wislizenii, or the flapfooted lizard, Lialis burtoni grip and apparently asphyxiate lizard prey (R. A. Anderson \& A. Herrl, pers. observ.), but also when male broadheaded skinks Eumeces laticeps trade bites during intrasexual combat (Cooper \& Vitt, 1993) or when male western whiptail lizards, Aspidoscelis tigris hold females during copulation (Anderson \& Vitt, 1990). The foregoing animals represent an opportunity to investigate how bite force relates both to gape size when biting and bite duration. Moreover, the mechanistic, musculoskeletal correlates (e.g. adductor muscle pennation, cross-sectional area, and fibre types, and the stretching of adductor muscle during gape) can be compared among age classes, sexes, and taxa as well.

The relationship of gape size to bite force has been tested explicitly only in bats, wherein a four-fold increase in gape angle decreased bite forces by as much as $40 \%$ in some species (Dumont \& Herrel, 2003). Musculoskeletal adjustments, however, can compensate for large gape. The grasshopper mouse Onychomys leucogaster kills rodent prey similar to its own body size by biting their skulls with the incisors. The grasshopper mouse has a much greater gape than related, seed-eating rodents, and it has an increased mechanical advantage in the masseters, despite their relatively smaller size (Satoh \& Iwaku, 2006). Although some preliminary evidence permits the inference that gape effects vary among lizards and that these differences may relate to differences in musculoskeletal patterns of adductors (A. Herrel, unpubl. data), explicit comparisons of bite force among designs of vertebrate jaw adductors have not been performed previously.

Open mouth threat displays in most vertebrates are presumed to be 'truth-in-advertising', as in sharks
(Barlow, 1974), crocodiles (Kofron, 1993), some lizards (Hertz, Huey \& Nevo, 1982; Greene, 1988; Marquez \& Cejudo, 2000; Lappin et al., 2006a), and many mammals (Szamado, 2003). If the proclivity to perform a threat display varies within conspecifics and congenerics, then it would be propitious to compare variation in that proclivity with variation in willingness to bite and maximal bite force (Lappin et al., 2006a).

\section{REPEATABILITY OF MAXIMAL BITES}

Among vertebrates, whether it is individuals varying in body size or among taxa with different hardness of prey, maximal bite forces of vertebrates are repeatable, both as measures of tetanic bite force in anaesthetized fish (Huber \& Motta, 2004) and in voluntary bites on force transducers by birds, turtles, and bats (intraclass correlation coefficients on regressions with body size were > 0.95; Aguirre et al., 2002; Herrel et al., 2002, 2005a). We tested for repeatability within adult individuals of the lizard T. teguixin. Maximum bite force on cantilevered bite bars within a single trial showed repeatability (Fig. 1). Moreover, their maximal bites were repeatable among trials (Fig. 2); the second strongest bites were always within $10 \%$ of the strongest bite even on trials separated by many weeks. Hence, we infer that bite force measurements by individuals that are presumably motivated to bite can be reliable indicators of maximal bite force capacity.

\section{EFFECTS OF TEMPERATURE AND MOTIVATIONAL STATE ON BITE PERFORMANCE}

In ectotherms such as lizards, temperature may have strong effects on whole-organism performance traits. Force generation at the muscular level has been suggested to be less sensitive to changes in temperature (Bennett, 1985). Bite force of the nocturnal lizards G. gecko, however, is significantly higher at $30^{\circ}$ body temperature than at $20^{\circ}$ (Fig. 3 ). Similarly, in agamid lizards, a $10^{\circ}$ decrease of the body temperature results in an approximately $50 \%$ decrease in bite force (Herrel et al., 1999b). Similarly, temperature-related changes were documented in the feeding kinematics of bluegill sunfish Lepomis macrochirus (Wintzer \& Motta, 2004).

Intrinsic factors affecting the motivational state of the animals may also affect bite force measurements. For example, we measured bite force of the aforementioned G. gecko during their activity period (night) and outside of it (day); they consistently bit harder at night (i.e. during their natural activity period) than during the day $(t=3.9$, d.f. $=9, P=0.004)$, despite being at the same body temperature (Fig. 4). Moreover, for each of four individual T. teguixin that we 


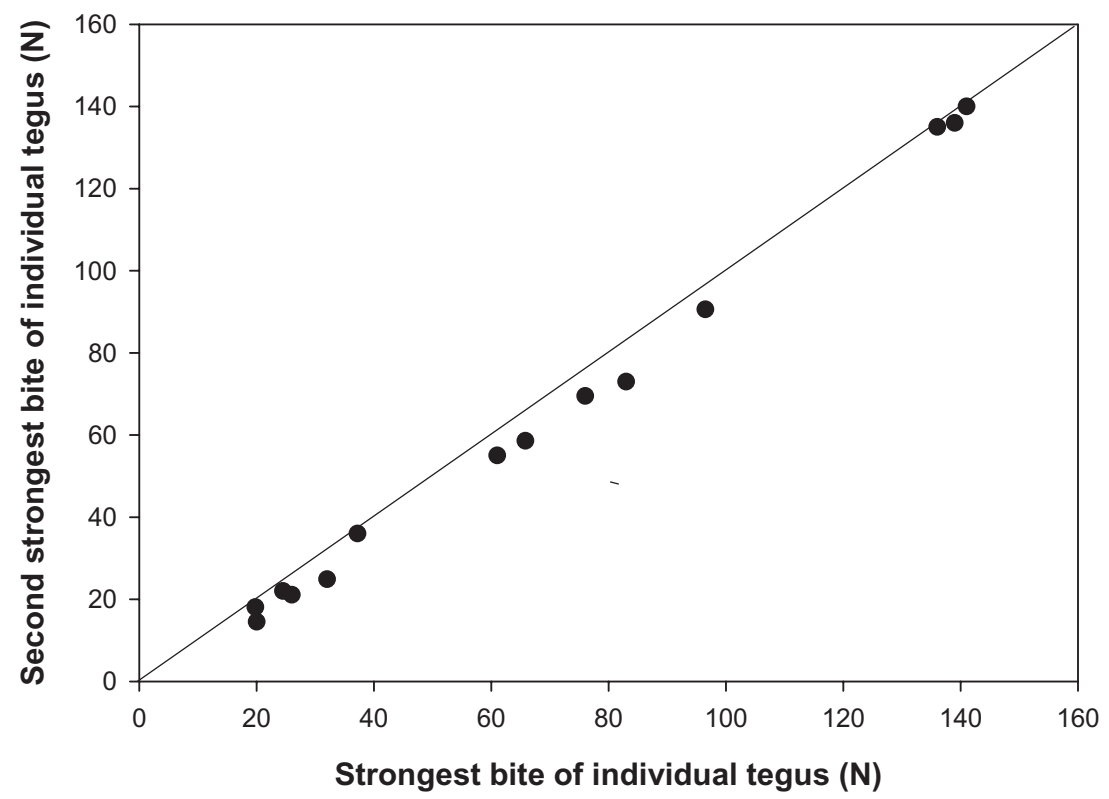

Figure 1. Repeatability of bite forces within a trial of bite force measurements for Tupinambis teguixin $\left(R^{2}=0.99\right.$, $P<0.001)$.

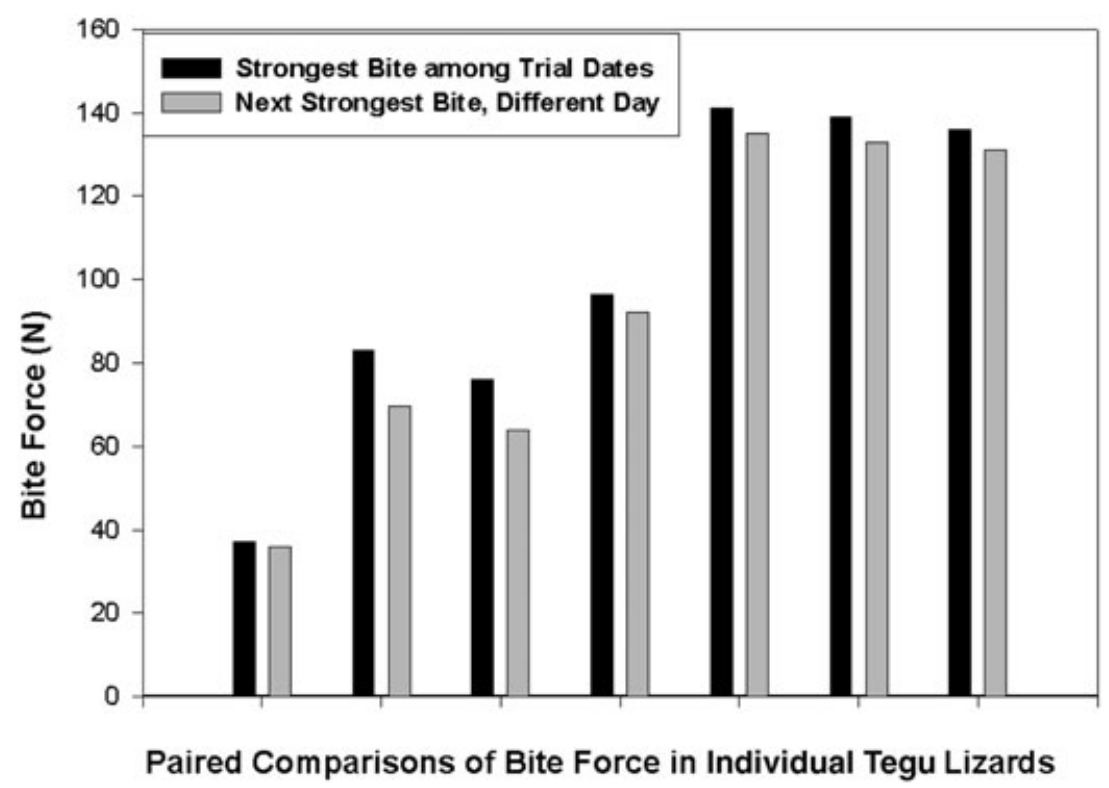

Figure 2. Repeatability of bite forces among trials (different days) of bite force measurements for Tupinambis teguixin $\left(R^{2}=0.99, P<0.001\right)$.

had fed versus post-absorptive bite force comparisons, the bite forces when the lizards were post-absorptive and presumably hungry were $46 \pm 1.9 \%$ higher on average than the bite forces when they still had food in their stomachs. This sample even included one unfed individual with a body temperature at $10^{\circ} \mathrm{C}$ less than when it was fed and at the likely field-active body temperature of $35{ }^{\circ} \mathrm{C}$. For four other individuals, the maximal bite forces when unfed and at $25{ }^{\circ} \mathrm{C}$ were $73,91,95$, and $96 \%$ of the maximal bite forces than when they were unfed and at $35{ }^{\circ} \mathrm{C}$. In a similar vein, satiation-related changes were seen in the feeding kinematics of the fish Micropterus salmoides (Sass \& Motta, 2002).

Seasonal variation in bite force has been reported for the lizard Anolis carolinensis (Irschick et al., 


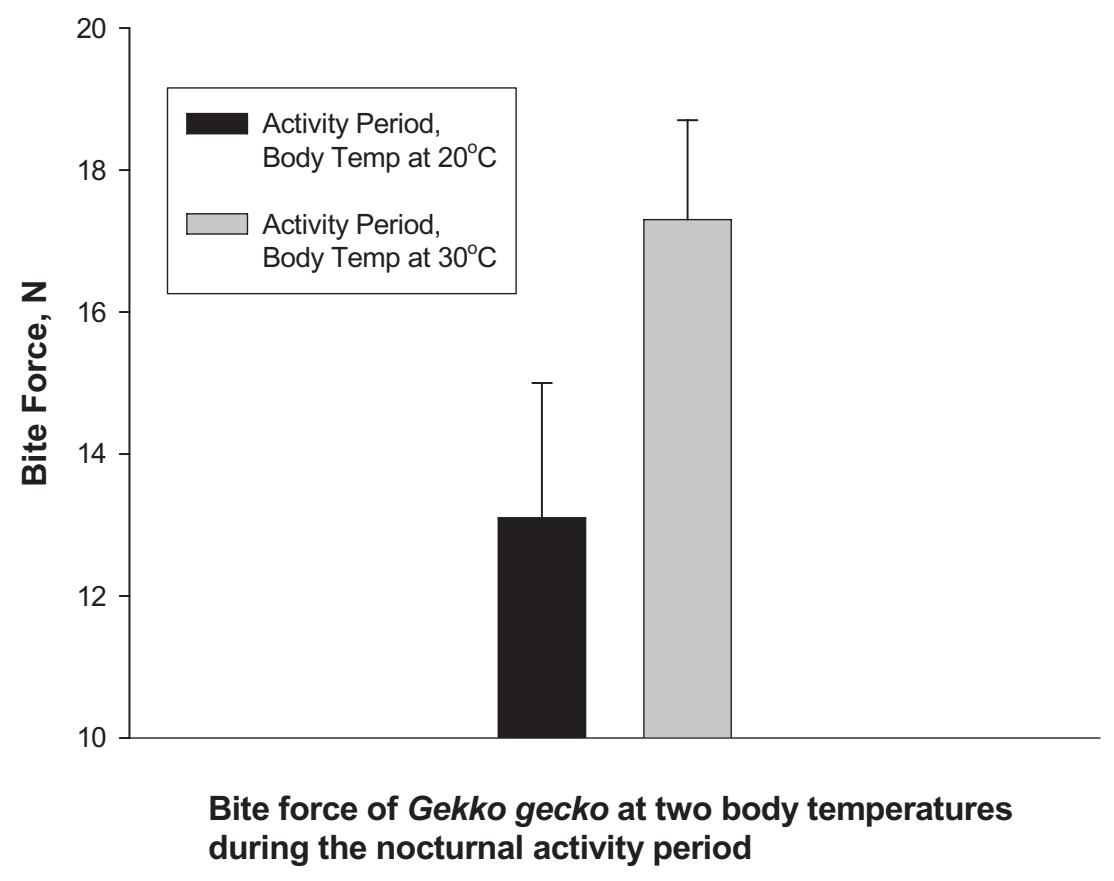

Figure 3. Gekko gecko bite forces compared: cool versus warm body temperatures $(N=10$, mean bite force $=17.7 \pm 1.4 \mathrm{~N}$ at $30{ }^{\circ} \mathrm{C}$ versus $12.0 \pm 1.9 \mathrm{~N}$ at $20^{\circ} \mathrm{C}$; paired $t$-test: $t=3.17, P=0.01$ ).

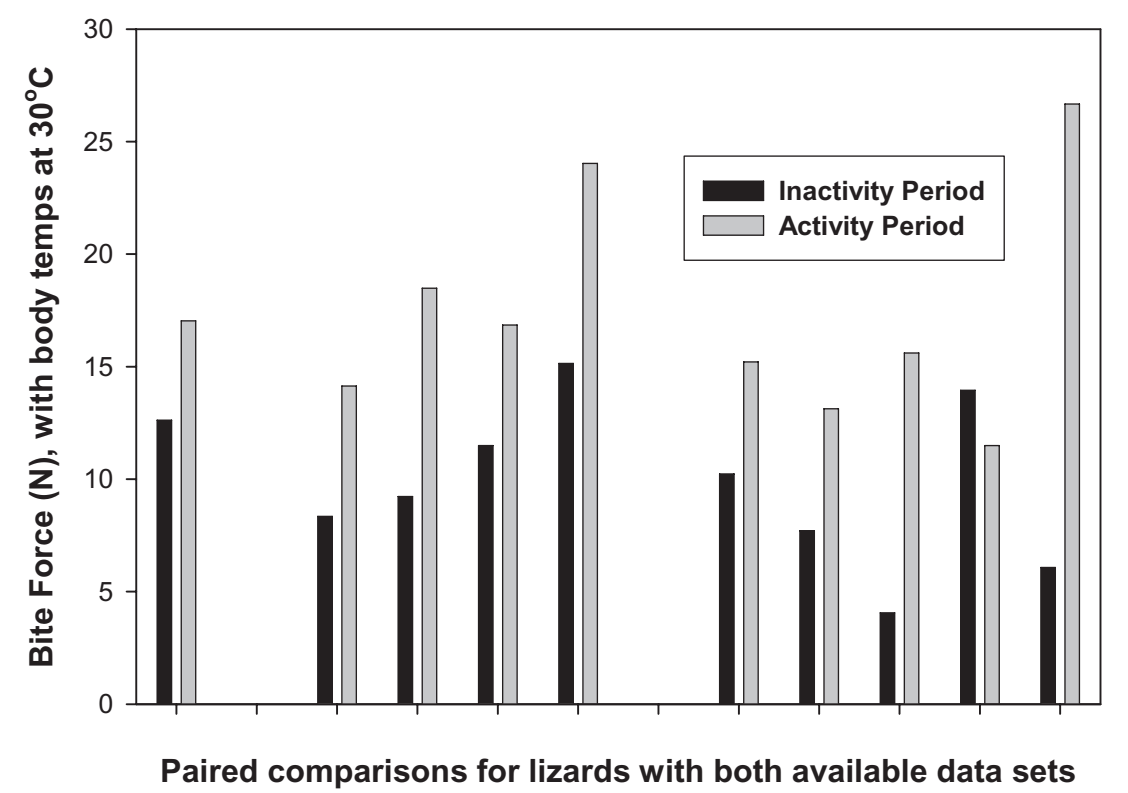

Figure 4. Gekko gecko bite forces at $30^{\circ} \mathrm{C}$ compared: inactivity period versus activity period. $(N=10$, paired $t$-test; $t=3.915, P=0.004)$.

2006). The seasonal patterns in hormone titre and male aggression correlate with seasonality in male head form in the broad-headed skink Eumeces laticeps (Cooper \& Vitt, 1993). It would be propitious to test these lizards for maximal bite force and relate it to motivation (Irschick et al., 2006) or actual seasonal hypertophy of adductor muscles.
Motivation to bite also appears to be higher earlier in a bite session, as was the case for T. teguixin. The strongest bites among all sessions for T. teguixin were the first bite in a session for ten of 13 individuals and the second bite in a session for the other three individuals. Similarly, the strongest bite happened in the first $30 \mathrm{~s}$ for ten of 14 adult $G$. gecko and, in seven of 
the 14 individuals, the first bite was the strongest. It is doubtful that fatigue is a factor in the reduced bite force later in the trials because bites that are almost as strong as the first bites do happen much later in the same bite trial. Thus, attention to the methods used, as well as the aforementioned temperaturerelated impairment, temperature-related motivation, and temporal variation (e.g. hormonal) in motivation to bite forcefully, should be assiduously compared with the actual ability to bite and the musculoskeletal correlates of bite force.

\section{MORPHOLOGICAL CORRELATES OF MAXIMAL BITE FORCE}

Maximal bite force is strongly correlated to body and head sizes for all taxa studied. Animals that are larger (Meyers, Herrel \& Birch, 2002; Erickson et al., 2003; Herrel \& O'Reilly, 2006) or with larger heads (Herrel et al., 1999a, 2001a, b, 2002; Verwaijen, Van Damme \& Herrel, 2002; Husak et al., 2006a; present study), bite harder. Among the different shape components of the head that could affect bite force, head width and height are usually the best predictors of maximal bite force capacity within and across species (Herrel et al., 1999a, 2001a, b, 2002, 2004). Despite the relatively low head height of the crevice-dwelling herbivorous lizard Sauromalus ater, its bite forces are considerable, especially in males (Lappin, Hamilton \& Sullivan, 2006b). Hence, beyond the simple indicators of head size, little is known about the proximate determinants of bite force in vertebrates.

Cross-sectional areas of the adductor muscles, muscle masses, and distribution of muscle fibre types, as well as extent of pennation and positions of the origin-and-insertion of muscles, in concert with the sizes, shapes (e.g. length, width, height, robustness, curvature) of the jaw and cranium, along with cranial kinesis (Frazetta, 1962; Arnold, 1998) and flexibility of the mandibular symphysis (Lieberman \& Crompton, 2000; Summers, 2000), should all be examined to understand how bite forces vary within and among species. Furthermore, there are many opportunities to study the effects of maturation on the form and function of the jaw-cranial complex and tooth morphotypes for species of vertebrates that ontogenetically shift prey (Erickson et al., 2003; Christiansen \& Adolfssen, 2005; Herrel \& O'Reilly, 2006; Irschick \& Lailvaux, 2006). These ontogenetic shifts can be compared with similar ecological 'shifts' among species. Moreover, these kinds of functional data may allow us to determine how much of the variation in bite performance is directly related to which musculoskeletal design components, thus revealing musculoskeletal structural constraints and opportunities in evolution of bite force in vertebrates.

\section{ECOLOGICAL SIGNIFICANCE OF MAXIMAL BITE FORCE}

If bite force is to be an effective whole-organism performance measure, then it must not only be correlated with morphotype and be repeatable within individuals, but also be commensurate with differences among individuals in an ecological outcome that is likely to have fitness consequences. For example, in laboratory studies of lizards, bite forces were correlated to handling times; individuals with higher bite forces needed less time to consume a given prey item (Herrel et al., 2001a; Verwaijen et al., 2002). Differences among species of bats and birds in the size and hardness of prey (i.e. prey types) eaten, directly correlated with differences in bite forces (Aguirre et al., 2002, 2003; Herrel et al., 2002, 2004; Van der Meij, Griekspoor \& Bout, 2004b). The increase in bite force with growth and maturation of individuals also may be related to changes in the prey spectrum or prey types consumed (Erickson et al., 2003; Herrel \& O'Reilly, 2006). That is, a greater bite force may increase proficiency in handling prey (i.e. the ability to capture, subdue, break, crush, and swallow prey in general, and harder and larger prey, in particular), thereby increasing the net rate of energy intake when foraging, and presumably enhancing fitness. Alternatively, just the presence of a hypertrophied jawcranial complex or other direct correlate of body size (sizes of mouth gape, teeth, or claws) may be enough to defeat conspecific competitors, thus avoiding the battle that could cause direct harm or attract predators (Vanhooydonck et al., 2005a). It is expected that the need for maximal bite force must occur at least once over an individual's lifetime or at least often enough in a particular lineage for the maximum bite to be maintained or hypertrophied within that lineage. The challenge for biologists is to obtain evidence that tightly links variation in whole animal performance such as maximal bite force with variation in fitness (Husak et al., 2006b).

\section{SEXUAL DIMORPHISM AND BITE FORCE}

The hypothesis that the differences in head size and body size between male and female teiid lizards should be mirrored by greater bite force of males than in females of the same body size (Anderson \& Vitt, 1990) is supported over a range of adult body sizes for T. teguixin (analysis of variance, $F=9.788, P<0.008$. $N=10$ females, $151-300 \mathrm{~mm}$ SVL, female regression: adjusted $R^{2}=0.97, \quad$ slope $=0.45, \quad$ intercept $=-49.9$; $N=6$ males, 146-312 mm SVL, male regression: adjusted $R^{2}=0.8$, slope $=0.58$, intercept $=-66.6$ ). In several other taxonomic families, the sex and age class with the larger head also bit with significantly more force (Herrel et al., 1999a, 2001a, b; Lailvaux et al., 2004; Lappin \& Husak, 2005; Husak et al., 
2006a; Lappin et al., 2006b; McBrayer \& Anderson, 2007). Thus, sexual dimorphism in head size is mirrored by a commensurate difference in bite force and, for at least one species, has been directly related to increases in cross sectional area and muscle volume (Herrel et al., 2007). This sexual difference in bite force may be a consequence of natural selection for reduced trophic competition (e.g. eating prey of different size or hardness) between the sexes (Herrel et al., 2001a; Verwaijen et al., 2002; Radford \& du Plessis, 2003) or could be the result of sexual selection for male bite performance or head size (Anderson \& Vitt, 1990; Herrel et al., 1996, 1999a; Lappin \& Husak, 2005; Lappin et al., 2006b; McBrayer \& Anderson, 2007).

Whereas support is scant for the hypothesis that fitness is conferred on individuals that exhibit greater differences in trophic structures (e.g. head and jaw size) from the opposite sex, there is support for the hypothesis that bite force is correlated with malemale combat in lizards. In staged contests between similarly sized males, the winning males typically have higher bite forces, at least among males in the larger size classes (Lailvaux et al., 2004; Huyghe et al., 2005). In lizards, bite forces may correlate with the size of sexual ornaments such as the dewlap in Anolis (Vanhooydonck et al., 2005b) and mouth patches in Crotaphytus (Lappin et al., 2006a). Moreover, dewlap size appears to be an honest indicator of male bite force (and thus fighting capacity) in territorial species but not others (Vanhooydonck et al., 2005b). Males of many lizard species also use their jaws to hold females prior to and during copulation (Anderson \& Vitt, 1990; Herrel et al., 1996). Biting performance in male lizards also may improve their chances of copulations with females (Lappin \& Husak, 2005). Even in species with females-larger sexual dimorphism in body size, males may have more robust jaw-cranial complexes than females of similar size, and thus may have greater bite force per unit body size than females (McBrayer \& Anderson, 2007).

\section{CONCLUSION}

We present evidence that maximal bite force is a useful performance trait that can be compared within and among species of organisms. That is, maximal bite force is repeatable for individuals within and among trials, and differences among individuals and between sexes in bite force are related to body size and the size and functional morphology of the jawcranial complex. Moreover, bite force is sensitive to temperature effects and motivation to bite. Because ethotypic, physiotypic, and morphotypic features are all involved and in play, bite force is a nonpareil whole-animal performance measure that has ecological and evolutionary relevance. Bite force is expected to affect the animal's fitness in the contexts of food acquisition, mate acquisition, and antipredation.

Future studies should investigate: (1) how bite force capacities vary among morphotypes of the jawcranial musculoskeletal complex; (2) field evidence of ecological significance of bite force; (3) effects of hormones and other proximal influences on bite force generation; (4) whether practice and experience in biting influences an individual's bite force capacities; (5) the heritability and fitness-conferring benefits of bite force, bite velocity, and bite duration; and (6) the ecologically relevant trade-offs in design features of the jaw-cranial musculoskeletal complex within and among species.

\section{ACKNOWLEDGEMENTS}

The double cantilever bite beam transducer was built for R.A.A. by the Electronics Design \& Maintenance Shop, University of Georgia Research Services (1990), and financed by SREL (UGA). University of Georgia (SREL), Berry College and SUNY College at Buffalo housed the T. teguxiin, and data collection on T. teguixin was initiated at Berry College and completed at SUNY Buffalo. Calibration tests on the R.A.A. meter were completed at WWU. WWU undergraduates Clayburn Lusk, Marc Van Winkle, Todd Phillips, Jon Hildahl, Darbie Cummings, and Jaymie Rennert helped collect data with respect to G. gecko in comparative vertebrate physiology laboratory classes. $R$. DiCaprio assisted L.D.M. in the construction of small portable force transducers. Peter Aerts and Jan Scholliers helped design and construct the bite force transducers used by A.H. A.H. is a postdoctoral fellow of the fund for scientific research Flanders (FWO-Vl).

\section{REFERENCES}

Aguirre LF, Herrel A, Van Damme R, Matthysen E. 2002. Ecomorphological analysis of trophic niche partitioning in a tropical savannah bat community. Proceedings of the Royal Society London Series B, Biologicak Sciences 269: 12711278.

Aguirre LF, Herrel A, Van Damme R, Matthysen E. 2003. The implications of food hardness for diet in bats. Functional Ecology 17: 201-212.

Anderson RA, Karasov WH. 1988. Energetics of the lizard, Cnemidophorus tigris, and life history consequences of food acquisition mode. Ecological Monographs 58: 79-110.

Anderson RA, Vitt LJ. 1990. Sexual selection versus alternative causes of sexual dimorphism in Teiid lizards. Oecologia 84: 145-157.

Arnold SJ. 1983. Morphology, performance, and fitness. American Zoologist 23: 347-361. 
Arnold EN. 1998. Cranial kinesis in lizards. Variation, uses, and origins. Evolutionary Biology 30: 323-357.

Barlow GW. 1974. Derivation of threat display in the gray reef shark. Marine. Behavior and Physiology 3: 71-81.

Beer FP, Johnston ER Jr, Clausen WE, Cornwell PJ. 2006. Vector mechanics for engineers, statics and dynamics. New York, NY: McGraw-Hill Scientific.

Bennett AF. 1985. Temperature and muscle. Journal of Experimental Biology 155: 333-344.

Binder WJ, Van Valkenburgh B. 2000. Development of bite strength and feeding behavior in juvenile spotted hyenas (Crocuta crocuta). Journal of Zoology 252: 273-283.

Bock WJ. 1964. Kinetics of the avian skull. Journal of Morphogy 114: 1-42.

Bock WJ, von Wahlert G. 1965. Adaptation and the formfunction complex. Evolution 19: 269-299.

Byron CD, Borke J, Yu J, Pashley D, Wingard CJ, Hamrick M. 2004. Effects of increased muscle mass on mouse sagittal suture morphology and mechanics. Anatomical Record 279: 676-684.

Christiansen P, Adolfssen JS. 2005. Bite forces, canine strength, and skull allometry in carnivores (Mammalia, Carnivora). Journal of Zoology 266: 133-151.

Cooper WE, Vitt LJ. 1993. Female mate choice of large male broad-headed skinks. Animal Behaviour 45: 683-693.

Dumont ER, Herrel A. 2003. The effects of gape angle and bite point on bite force in bats. Journal of Experimental Biology 206: 2117-2123.

Erickson GM, Lappin AK, Van Vliet KA. 2003. The ontogeny of bite-force performance in American alligator (Alligator mississippiensis). Journal of Zoology 260: 317327.

Frazetta TH. 1962. A functional consideration of cranial kinesis in lizards. Journal of Morphology 111: 287319.

Greene HW. 1988. Antipredator mechanisms in reptiles. In: Gans C, Pough FH, eds. Biology of the reptilia. New York, NY: Alan R. Liss, 1-152.

Grubich J. 2003. Morphological convergence of pharyngeal jaw structure in durophagous perciform fish. Biological Journal of the Linnean Society 80: 147-165.

Grubich J. 2005. Disparity between feeding performance and predicted muscle strength in the pharyngeal musculature of black drum, Pogonias cromis (Sciaenidae). Environmental Biology of Fishes 74: 261-272.

Hernandez LP, Motta PL. 1997. Trophic consequences of differential performance in the sheepshead, Archsargus probatocephalus (Teleostei, Sparidae). Journal of Zoology 243: 737-756.

Herrel A, Aerts P, De Vree F. 1998a. Static biting in lizards: functional morphology of the temporal ligaments. Journal of Zoology 244: 135-143.

Herrel A, Aerts P, De Vree F. 1998b. Ecomorphology of the lizard feeding apparatus: a modeling approach. Netherlands Journal of Zoology 48: 1-25.

Herrel A, Aerts P, De Vree F. 2000. Cranial kinesis in gekkonids lizards: functional implications. Journal of Experimental Biology 203: 1415-1423.
Herrel A, Aerts P, Fret J, De Vree F. 1999b. Morphology of the feeding system in agamid lizards: ecological correlates. Anatomical Record. 254: 496-507.

Herrel A, De Grauw E, Lemos-Espinal JA. 2001b. Head shape and bite performance in Xenosaurid lizards. Journal of Experimental Zoology 290: 101-107.

Herrel A, De Vree F, Delheusy V, Gans C. 1999c. Cranial kinesis in gekkonids lizards. Journal of Experimental Biology 202: 3687-3698.

Herrel A, Joachim R, Vanhooydonck B, Irschick DJ. 2006. Ecological consequences of ontogenetic changes in head shape and bite performance in the Jamaican lizard Anolis lineatopus. Biological Journal of the Linnean Society 89: $443-454$.

Herrel A, McBrayer LD, Larson P. 2007. Functional basis for intersexual differences in bite force in the lizard Anolis carolinensis. Biological Journal of the Linnean Society 91: 111-119.

Herrel A, O'Reilly JC. 2006. Ontogenetic scaling of bite force in lizards and turtles. Physiological and Biochemical Zoology 79: 31-42

Herrel A, O'Reilly JC, Richmond AM. 2002. Evolution of bite performance in turtles. Journal of Evolutionary Biology 15: $1083-1094$

Herrel A, Podos J, Huber SK, Hendry AP. 2005a. Bite performance and morphology in a population of Darwin's finches: implications for the evolution of beak shape. Functional Ecology 19: 43-48.

Herrel A, Podos J, Huber SK, Hendry AP. 2005b. Evolution of bite force in Darwin's finches: a key role for head width. Journal of Evolutionary Biology 18: 669-675.

Herrel A, Spithoven L, Van Damme R, De Vree F. 1999a. Sexual dimorphism of head size in Gallotia galloti: testing the niche divergence hypothesis by functional analyses. Functional Ecology 13: 289-297.

Herrel A, Van Damme R, DeVree F. 1996. Sexual dimorphism of head size in Podarcis hispanica: testing the dietary divergence hypothesis by bite force analysis. Netherlands Journal of Zoology 46: 253-262.

Herrel A, Van Damme R, Vanhooydonck B, De Vree F. 2001a. The implications of bite performance for diet in two species of lacertid lizards. Canadian Journal of Zoology 79: $662-670$

Herrel A, Van Wassenbergh S, Wouters S, Aerts P, Adriaens D. 2005c. A functional morphological approach to the scaling of the feeding system in the African catfish, Clarias gariepinus. Journal of Experimental Biology 208: 2091-2102.

Herrel A, Vanhooydonck B, Van Damme R. 2004. Omnivory in lacertid lizards: adaptive evolution or constraint? Journal of Evolutionary Biology 17: 974-984.

Hertz PE, Huey RB, Nevo E. 1982. Fight v. flight: body temperature influences defensive responses of lizards. Animal Behaviour 30: 676-679.

Huber DR, Eason TG, Hueter RE, Motta PJ. 2005. Analysis of the bite force and mechanical design of the feeding mechanism of the durophagous horn shark Heterodontus francisci. Journal of Experimental Biology 208: 3553-3571. 
Huber DR, Motta PJ. 2004. Comparative analysis of methods for determining bite force in the spiny dogfish Squalus acanthias. Journal of Experimental Zoology 301A: 26-37.

Huey RB, Stevenson RD. 1979. Integrating thermal physiology and ecology of ectotherms: a discussion of approaches. American Zoologist 19: 357-366.

Husak JF, Fox SF, Lovern MB, Van Den Bussche RA. 2006b. Faster lizards sire more offspring: sexual selection on whole-animal performance. Evolution 60: 21222130 .

Husak JF, Lappin AK, Fox SF, Lemos-Espinal JA. 2006a. Bite force performance predicts dominance in male venerable collared lizards (Crotaphytus antiquus). Copeia 2006: 301-306.

Huyghe K, Vanhooydonck B, Scheers H, Molina-Borja M, Van Damme R. 2005. Morphology, performance and fighting capacity in male lizards, Gallotia galloti. Functional Ecology 19: 800-807.

Irschick DJ, Garland T. 2001. Integrating function and ecology in studies of adaptation: investigations of locomotor capacity as a model system. Annual Review of Ecology and Systematics 32: 367-396.

Irschick DJ, Lailvaux SP. 2006. Age-specific forced polymorphism: implications of ontogenetic changes in morphology for male mating tactics. Physiological and Biochemical Zoology 79: 73-82.

Irschick DJ, Ramos M, Buckley C, Esltrot J, Carlisle E, Lailvaux SP, Bloch N, Herrel A, Vanhooydonck B. 2006. Are morphology-performance relationships invariant across different seasons? A test with the green anole (Anolis carolinensis). Oikos 114: 49-59.

Kofron CP. 1993. Behavior of Nile crocodiles in a seasonal river in Zimbabwe. Copeia 1993: 463-469.

Korff WL, Wainwright PC. 2004. Motor pattern control for increasing crushing force in the striped burrfish (Chylomycterus schoepfi). Zoology 107: 335-346.

Lailvaux SP, Herrel A, Vanhooydonck B, Meyers JJ, Irschick DJ. 2004. Performance capacity, fighting tactics and the evolution of life-stage male morphs in the green anole lizard (Anolis carolinensis). Proceedings of the Royal Society London Series B, Biological Sciences 271: 25012508.

Lappin AK, Brandt Y, Husak JF, Macedonia JM, Kemp DJ. 2006a. Gaping displays reveal and amplify a mechanically based index of weapon performance. American Naturalist 168: 100-113.

Lappin AK, Hamilton PS, Sullivan BK. 2006b. Bite force performance and head shape in a sexually dimorphic crevice-dwelling lizard, the common chuckwalla [Sauromalus ater (= obesus)]. Biological Journal of the Linnean Society 88: 215-222.

Lappin AK, Husak JF. 2005. Weapon performance, not size, determines mating success and potential reproductive output in the collared lizard (Crotaphytus collaris). American Naturalist 166: 426-436.

Levinton JS, Allen BJ. 2005. The paradox of the weakening combatant: trade-off between closing force and gripping speed in a sexually selected combat structure. Functional Ecology 19: 159-165.

Levinton JS, Judge ML. 1993. The relationship of closing force to body size for the major claw of Uca pugnax (Decapoda: Ocypodidae). Functional Ecology 7: 339.

Lieberman DR, Crompton AW. 2000. Why fuse the mandibular symphysis? A comparative analysis. American Journal of Physical Anthropology 112: 517-540.

McBrayer LD. 2002. Comparative studies in the functional morphology of lizard feeding: kinematics, behavior, and biomechanics. DPhil Thesis, Ohio University.

McBrayer LD. 2004. The relationship between skull morphology, biting performance and foraging mode in Kalahari lacertid lizards. Zoological Journal of the Linnean Society 140: 403-416.

McBrayer LD, Anderson RA, 2007. Sexual dimorphism in head shape and bite force in the Northern Alligator lizard, Elgaria coerulea. Journal of Herpetology 41: 554-559.

McBrayer LD, White TD. 2002. Bite force, behavior, and electromyography in the teiid lizard, Tupinambis Teguixin. Copeia 2002: 111-119.

Marquez R, Cejudo D. 2000. Defensive behavior as an escape strategy in four species of Gallotia (Sauria, Lacertidae) from the Canary Islands (Spain). Copeia 2000: 601-605.

Measey J, Herrel A. 2006. Rotational feeding in caecilians: putting a spin on the evolution of cranial design. Biology Letters 2: 485-487.

van der Meij MAA, Bout RG. 2004a. Scaling of jaw muscle size and maximal bite force in finches. Journal of Experimental Biology 207: 2745-2753.

Meyers JJ, Herrel A, Birch J. 2002. Scaling of morphology, bite force and feeding kinematics in an iguanian and a scleroglossan lizard. In: Aerts P, D'aout K, Herrel A, Van Damme R, eds. Topics in functional and ecological vertebrate morphology. Maastricht: Shaker Publishing, 47-62.

Motta PJ, Kotrschal KM. 1992. Correlative, experimental, and comparative evolutionary approaches in ecomorphology. Netherlands Journal of Zoology 42: 400-415.

Radford AN, du Plessis MA. 2003. Bill dimorphism and foraging niche partitioning in the green woodhoopoe. Journal of Animal Ecology 72: 258-269.

Ross CF, Dharia R, Herring SW, Hylander WL, Liu Z, Rafferty KL, Ravosa MJ, Williams SH. 2007. Modulation of mandibular loading and bite force in mammals during mastication. Journal of Experimental Biology 210: 10461063.

Sass GG, Motta PL. 2002. The effects of satiation on strike mode and prey capture kinematics in the largemouth bass Micropterus salmoides. Environmental Biology of Fishes 65: 441-454.

Satoh K, Iwaku F. 2006. Jaw muscle functional anatomy in northern grasshopper mouse, Onychomys leucogaster, a carnivorous murid. Journal of Morphology 267: 987-999.

Schenk SC, Wainwright PC. 2001. Dimorphism and the functional basis of claw strength in six brachyuran crabs. Journal of Zoology 255: 105-119. 
Schoener TW. 1966. The ecological significance of sexual dimorphism in size in the lizard Anolis conspersus. Science (Washington D.C.) 155: 474-476.

Sinclair AG. 1983. The mechanics of feeding of reptiles. DPhil Thesis, University of Leeds.

Summers AP. 2000. Stiffening the stingray skeleton-an investigation of durophagy in Myliobatid stingrays (Chondrichythyes, Batoidea, Myliobatidae). Journal of Morphology 243: 113-126.

Szamado S. 2003. Threat displays are not handicaps. Journal of Theoretical Biology 221: 327-348.

Taylor GM. 2000. Maximum force production: why are crabs so strong.? Proceedings of the Royal Society Biological Sciences Series B, Biological Sciences 267: 14751480.

Taylor GM. 2001. The evolution of armament strength: evidence for a constraint on the biting performance of claws of durophagous decapods. Evolution 55: 550-560.

Thompson EN, Biknevicius AR, German RZ. 2003. Ontogeny of feeding function in the gray short-tailed opossum Monodelphis domestica: empirical support for the constrained model of jaw biomechanics. Journal of Experimental Biology 206: 923-932.

Van Damme R, Wilson RS, Vanhooydonck B, Aerts P. 2002. Performance constraints in decathletes. Nature 415: 755-756.

Van der Meij MAA, Griekspoor M, Bout RG. 2004b. The effect of seed hardness on husking time in finches. Animal Biology 54: 195-205.

Vanhooydonck B, Herrel A, Van Damme R, Irschick DJ. 2005b. Does dewlap size predict male bite force in Jamaican Anolis lizards? Functional Ecology 19: 38-42.

Vanhooydonck B, Herrel A, Van Damme R, Meyers JJ, Irschick DJ. 2005a. The relationship between dewlap size and performance changes with age and sex in a Green Anole (Anolis carolinensis) lizard population. Behavioral Ecology and Sociobiology 59: 157-165.

Vanhooydonck B, Van Damme R, Aerts P. 2001. Speed and stamina trade-off in lacertid lizards. Evolution 55: 1040-1048.

Verwaijen D, Van Damme R, Herrel A. 2002. Relationships between head size, bite force, prey handling efficiency and diet in two sympatric lacertid lizards. Functional Ecology 16: $842-850$.

Wainwright PC. 1991. Ecomorphology: experimental functional anatomy for ecological problems. American Zoologist 31: 680-693.

Wilga CD, Motta PJ. 2000. Durophagy in sharks: feeding mechanics of the hammerhead Sphyrna tiburo. Journal of Environmental Biology 203: 2781-2796.

Wintzer AP, Motta PJ. 2004. The effects of temperature on prey-capture kinematics of the bluegill (Lepomis macrochirus): implications for feeding studies. Canadian Journal of Zoology 82: 794-799. 